\title{
Gas Breakthrough Pressure (GBP) through Claystones: Correlation with FIB/SEM Imaging of the Pore Volume
}

\author{
Yang Song ${ }^{1,2}$, Catherine A. Davy ${ }^{1 *}$ and David Troadec ${ }^{3}$ \\ 'École Centrale de Lille, Cité Scientifique, CS20048, 59651 Villeneuve d'Ascq Cedex - France \\ ${ }^{2}$ Changzhou Institute of Technology, Chang Zhou Gong Xue Yuan, 213000 Changzhou Shi, Jiangsu Sheng - China \\ ${ }^{3}$ Institut d'Électronique, de Micro-Électronique et de Nanotechnologie (IEMN), UMR CNRS 8520, BP 60069, 59652 Villeneuve d'Ascq - France \\ e-mail: catherine.davy@ec-lille.fr \\ * Corresponding author
}

\begin{abstract}
This contribution uses six claystone samples imaged by FIB/SEM (Focused Ion Beam/ Scanning Electron Microscopy), within micrometric volumes located in the clay matrix; their $3 D$ connected pore network is identified down to 17-22 $\mathrm{nm}$ pore size. All samples are gently dried to minimize damage, and several are impregnated with Poly(Methyl MethAcrylate) (PMMA) resin to avoid further damage during FIB/SEM observations. Three pore volumes out of six are connected between two parallel end surfaces through crack-like pores; two are not connected between any two parallel end surfaces; only one sample has a connected pore network distinct from cracks.

By assuming varied pathways for gas to migrate by capillarity through the connected pore volumes (either by taking the shortest path, or through the largest path, or through the most frequent pore size, or by simulating the ingress of a non wetting fluid), we determine the Gas Breakthrough Pressure (GBP) through the initially fully liquid saturated claystone, from these micrometric volumes. The scale change (from the micrometric to the macroscopic scale) is assumed possible without changing the GBP value, and clay/water interactions are not accounted for. By comparison with GBP values measured in the laboratory on centimetric-sized claystone samples, it is concluded that breakthrough occurs most probably by capillary digitation; micro-cracks are the most probable pathways for gas, so that gas does not progress in a homogeneous manner through the claystone, as standard macroscopic finite element models would represent it. For intact claystone, predictions based on the capillary ingress of a non wetting fluid provide a GBP value ranging between 7-14 MPa.
\end{abstract}

Résumé - Corrélations entre Pression de Percée de Gaz (PPG) et imagerie FIB/MEB de roches argileuses (argilites) - Six échantillons de roches argileuses (argilites) sont observés au FIF/MEB (Faisceau d'Ions Focalisé couplé à un Microscope Électronique à Balayage) au sein de volumes micrométriques situés dans la matrice argileuse (seule partie poreuse du matériau). Les échantillons sont séchés de façon à minimiser leur endommagement, et imprégnés ou non de résine polyméthacrylate de méthyle (PMMA) pour les maintenir lors des observations. Le réseau poreux connecté en 3D de ces échantillons est mesuré jusqu'à des tailles de pores de 17-22 nm de diamètre. Trois réseaux poreux sur six sont connectés par des pores de morphologie identique à des fissures ; deux réseaux poreux ne sont pas connectés entre deux faces paralléles de l'échantillon ; un seul réseau poreux (sur six) est connecté par des pores qui ne correspondent pas à des fissures.

En supposant différents modes de transport capillaire (via le chemin le plus court, via le chemin le plus large, via la taille de pore la plus fréquente, ou en simulant l'intrusion de fluide non mouillant) à l'échelle de ces réseaux poreux micrométriques, nous déterminons la Pression de Percée de Gaz (PPG) au travers 
de la roche initialement saturée de liquide. On suppose que le changement d'échelle est possible sans altération de la PPG, et que les interactions eau/argile sont négligeables. En comparant nos prédictions avec les valeurs expérimentales mesurées au laboratoire, nous montrons que la percée se produit avec la plus grande probabilité par digitation capillaire, via un volume limité de pores, qui ont une morphologie de fissures, et pas de façon homogène au travers de la roche argileuse, comme cela peut être représenté de façon simplifiée dans un modèle standard par Élements Finis. Pour le matériau intact, les prédictions basées sur l'intrusion capillaire de fluide non mouillant donnent une PPG variant entre 7 et $14 \mathrm{MPa}$.

\section{INTRODUCTION}

\section{Industrial Context}

In industrialized countries, a major societal issue is the longterm management of long-lived and medium to high activity radioactive waste. In France, their deep underground storage is planned within a Callovo-Oxfordian (COx) claystone formation located at about $500 \mathrm{~m}$ depth in the East of the Paris Basin [1]. An Underground Research Laboratory (URL) exists there, with several kilometers tunnels already drilled and instrumented; Andra (Agence Nationale pour la gestion des Déchets RAdioactifs) is in charge of managing the site and the research regarding the safety assessment of the system. A second URL exists in the South of France (at Tournemire, Aveyron), where the host rock is a Toarcian claystone; it is managed by IRSN (Institut de la Radioprotection et de la Sûreté Nucléaire).

Ensuring a safe underground storage is managed through the so-called engineered barrier, which comprises waste vitrification, metallic or concrete casing around the storage tunnels, sealing with swelling clay plugs, and a whole specifically-designed structure. The COx claystone host rock is also a determining component in retaining any radionucleide within the structure.

In particular, after the drilling of storage tunnels, macrofracturing is observed in a so-called Excavated Damaged Zone (EDZ) located close to the tunnel surface. Underground water seepage is shown to allow self-sealing of the EDZ [1], so that water permeability recovers values on the order of the undisturbed claystone (i.e. $10^{-20}-10^{-21} \mathrm{~m}^{2}$ i.e. 1-10 nD). However, after the filling and closure of the storage tunnels, hydrogen gas may develop and progressively pressurize inside the repository, due to varied physicochemical phenomena [2-4]. In this context, one of the aims of the Engineered Barrier and of the host rock is to retain the gas.

As a consequence, the conditions for proper gas immobilization within the underground site, in the self-sealed zone and in the undisturbed matter, away from the repository, need to be assessed. This may be investigated (among other methods) by:

- identifying experimentally the Gas Breakthrough Pressure (GBP) across fully water-saturated claystone, as in $[2,3,5]$, or

- predictions using an accurate characterization of the pore network combined to a well-chosen physical model for fluid migration.

It is the latter that we propose to do in this contribution.

\section{State-of-the-Art}

\section{Characterization of the Pore Network}

The adequate characterization of the pore network of claystones is complex to gain. Indeed, the COx claystone is made of a range of minerals, comprising mainly tectosilicates, carbonates, pyrite, and, most importantly, clays. Whereas tectosilicates, carbonates, and pyrite are reputed non porous, they display porous interfaces with clays, and clays themselves display a wide range of pore sizes ${ }^{1}$. On the whole, the pore size distribution of COx claystone ranges from below $1 \mathrm{~nm}$ (micropores) and up to several hundred nanometers (i.e. both meso- and macropores) [4, 6-8].

While indirect methods span the whole pore size range, with only one or two techniques (Mercury Intrusion Porosimetry (MIP), nitrogen or $\mathrm{CO}_{2}$ adsorption), these generally require to model the pore network as the assembly of individual non connected circular cylindrical pores of varying diameter. This over-simplification is not necessary when using direct imaging techniques, such as X-Ray Computed Micro-Tomography (X-Ray CMT), Broad or Focused Ion Beam/Scanning Electron Microscopy (BIB/SEM or FIB/ SEM), or Transmission Electron Microscopy (TEM) in order to image the pores in $2 \mathrm{D}$ or $3 \mathrm{D}$ [6-16]. However, any imaging technique is limited by the fact that the smaller the pixel (or voxel) size is, the smaller the sample size is.

\footnotetext{
${ }^{1}$ Throughout this contribution, unless otherwise stated, pore size refers to pore diameter.
} 
The representativeness of the imaged zone is not ensured with a single sample up to the macroscopic scale. A solution is to image as many zones as possible, and provide pore properties in a statistical sense $[8,15]$.

In the particular case of claystones, an additional difficulty occurs, which is the fineness of their pores. For instance, although using a voxel size of $700 \mathrm{~nm}$, X-Ray CMT has been able to image only $0.5 \%$ of COx claystone porosity, whereas its total porosity given by indirect techniques is of $18 \pm 4 \%[17,18]$; this $0.5 \%$ relative pore volume is only made of scattered, non connected pores, so that no fluid transport may be predicted through them without further assumptions. Former research on COx claystone and Opalinus clay $[6-8,16]$ has shown that FIB/SEM combined to TEM provides a reliable assessment of the connected 2D and $3 \mathrm{D}$ pore networks of these claystones down to less than one $\mathrm{nm}$, which is consistent with indirect measurements; these pores are located within the clay matrix (in contrast to the non porous carbonate and tectosilicate grains that claystones contain). For the COx, two peak pore sizes are determined by a combination of imaging techniques at 4-6 nm (TEM) and $50 \mathrm{~nm}$ (FIB/SEM) [8], i.e. within mesopores [19], in good agreement with Andra reference data [4].

\section{Gas Migration Mechanisms}

Extensive research exists on the experimental identification of gas breakthrough properties of low permeability media $[3,20-23]$. In general, at the laboratory scale, the initial conditions are a fully water-saturated medium subjected to a gas pressure of given amplitude, until gas passage is detected by varying means. However, no consensus exists as the exact phenomena involved in the gas migration (or breakthrough) through water-saturated clayrocks [3, 20, 22, 24-29]. Rather, several mechanisms are considered.

The well-known description by Marschall et al. [28] considers four different mechanisms leading to gas migration. These may occur simultaneously or separately, depending on the porous material or on the poro-mechanical loading considered.

The first migration mechanism consists in gas dissolution within pore water, followed by the transport of dissolved gas by diffusion and/or convection through the pore network. This phenomenon occurs systematically, yet to a limited extent for laboratory experiments, owing to the relatively short time needed to reach breakthrough (3-5 days for 1-3 cm long COx claystone samples, whereas first order calculations provide 13-123 days for a passage by dissolution/diffusion) [3, 5].

Secondly, a visco-capillary two-phase flux is considered. It is associated with negligible changes in the solid skeleton volume. In such instance, gas starts to penetrate the pore network; this occurs at the so-called gas entry pressure; then, gas progresses through the pore network due to capillary and viscous forces, and creates channels or pathways. Together with dissolution and diffusion through the pore fluid, this description by capillary action is privileged by $[22,24]$ for finely porous clayey materials; it does not mention the necessity of claystone damage for gas to migrate. In this contribution, we assume that the visco-capillary mechanism explains Gas Breakthrough (GB) through initially fully liquid saturated COx claystone. In particular, the Laplace's (or Washburn's) law is used to predict the location of the interface between gas and liquid as:

$$
P_{\text {gas }}-P_{\text {water }}=P_{c}=\frac{2 \gamma}{r}
$$

where $P_{\text {gas }}$ is the pressure in the gas phase, $P_{\text {water }}$ is the pressure in the water phase, $P_{c}$ is the so-called capillary pressure, $\gamma$ is the surface tension at the interface between gas and liquid and $r$ is the pore radius at the gas/water interface. In the following, in a first approach, $\gamma$ is taken equal to $7.275 \times 10^{-2} \mathrm{~N} / \mathrm{m}$, which is the usual value for the interface between air and water.

In the third mechanism, gas passage is allowed by pore network dilatancy. Gas migrates by progressive tensile failure and micro-cracking of the solid skeleton, and by dilating the width of gas pathways to increase its passage [25, 26, 30]. This mechanism requires gas pressures of sufficient magnitude to counterbalance the local compressive stress state (reproducing the in situ loading), and to reach the material tensile strength. It is favored in the case of claystones, which possess very low tensile strength [29].

The fourth mechanism is an amplification of the third one: it is hydraulic fracturing, whereby breakthrough occurs along macroscopic tensile fractures.

\section{Aims and Scopes}

Our former research $[8,31]$ has identified the pore volumes of both COx and Tournemire claystones, down to 17-22 nm pore size, for six micrometric volumes. These are specifically located in the clay matrix, which is the porous part of these claystones.

Among the six micrometric volumes (Tab. 1), one is of Tournemire claystone (Tournemire-1 sample), whereas the five others are taken in the COx, from two distinct cores (EST26095 and EST27405). Their clay content is 37\% (EST26095), 50\% (EST27405) or 66.6\% (Tournemire-1); their total porosity (at the macroscopic scale) is $12.9-14.8 \%$ (EST26095), $17.5-20.0 \% \quad$ (EST27405) or $8 \% \pm 2$ (Tournemire).

To allow FIB/SEM imaging and limit sample damage (by micro-cracking), the Tournemire- 1 sample is dried at $100^{\circ} \mathrm{C}$ and impregnated in epoxy resin, whereas the $\mathrm{COx}$ 
TABLE 1

General characteristics of the six claystone samples imaged by FIB/SEM $[8,31]$ and analyzed herein for GBP. Porosity is determined after segmentation by the Yen algorithm available in ImageJ

\begin{tabular}{|c|c|c|c|c|c|}
\hline $\begin{array}{c}\text { Sample name } \\
\text { (core no. + number) }\end{array}$ & Sample orientation & $\begin{array}{l}\text { Sample size } \\
\qquad\left(\mu \mathrm{m}^{3}\right)\end{array}$ & $\begin{array}{l}\text { Voxel size } \\
\quad\left(\mathrm{nm}^{3}\right)\end{array}$ & $\begin{array}{l}\text { Porosity }(\%)(\text { Yen } \\
\text { segmentation } \\
\text { algorithm) }\end{array}$ & Connectivity \\
\hline EST27405-1 & $\begin{array}{l}\text { Perpendicular to } \\
\text { bedding planes }\end{array}$ & 53.8 & $8.49 \times 10.78 \times 10$ & $\begin{array}{c}2.80 \\
0.79 \text { (connected only) }\end{array}$ & $\begin{array}{c}\text { Yes, only } \\
\text { through cracks }\end{array}$ \\
\hline EST27405-2 & $\begin{array}{l}\text { Perpendicular to } \\
\text { bedding planes }\end{array}$ & 27.8 & $5.94 \times 7.54 \times 10$ & $\begin{array}{c}4.90 \\
2.10 \text { (connected only) }\end{array}$ & $\begin{array}{l}\text { Yes, only } \\
\text { through cracks }\end{array}$ \\
\hline EST26095-1 & $\begin{array}{c}\text { Parallel to bedding } \\
\text { planes }\end{array}$ & 146.7 & $8.48 \times 10.77 \times 20$ & 0 (connected only) & No \\
\hline EST26095-2 & $\begin{array}{l}\text { Parallel to bedding } \\
\text { planes }\end{array}$ & 88.9 & $8.48 \times 10.77 \times 20$ & $\begin{array}{c}5.90 \\
0.73 \text { (connected only) }\end{array}$ & Yes no cracks \\
\hline EST26095-3 & $\begin{array}{c}\text { Parallel } \\
\text { to bedding planes }\end{array}$ & 111.4 & $8.49 \times 10.78 \times 20$ & $\begin{array}{c}5.21 \\
0 \text { (connected only) }\end{array}$ & No \\
\hline Tournemire-1 & $\begin{array}{l}\text { Perpendicular to } \\
\text { bedding planes }\end{array}$ & 553.1 & $8.49 \times 10.78 \times 50$ & $\begin{array}{c}3.64 \text { (with cracks) } \\
0.68 \text { (connected only) }\end{array}$ & $\begin{array}{c}\text { Yes, only } \\
\text { through cracks }\end{array}$ \\
\hline
\end{tabular}

EST26095 samples are more gently dried at $80^{\circ} \mathrm{C}$ and impregnated with PMMA [17]. The COx EST27405 samples are also gently dried at $80^{\circ} \mathrm{C}$, but they are imaged without any preliminary resin impregnation. PMMA is chosen for its very low viscosity before polymerization (it is close to that of liquid water), whereas the absence of resin impregnation is expected to yield greater sample micro-cracking. The non impregnated claystone (EST27405) is assumed more representative of the EDZ than PMMA-impregnated matter (EST26095); PMMA-impregnated claystone is only subjected to desiccation and potential cracking during the gentle $80^{\circ} \mathrm{C}$ drying, whereas non impregnated matter sustains the continuous drying effect of the microscope vaccuum pumps. Moreover, former research by Robinet et al. [17] uses PMMA-impregnated COx claystone of the same core as here (EST26095), yet for X-Ray CMT imaging; we aim to provide comparable datasets to [17], although on a smaller scale (down to 17-22 nm instead of $700 \mathrm{~nm}$ ). In [8], we have also chosen to use PMMA-impregnated COx claystone to perform TEM imaging, because sample thinning is significantly eased by this strengthening means.

Following image segmentation [8] by the same procedure for all samples, we observe that four out of the six FIB/SEM samples have a connected pore volume, of 0.68 to $2.10 \%$ (Tab. 1, penultimate column to the right); the two other samples (of COx claystone) have no connected pore volume down to $17 \mathrm{~nm}$ pore size $(8.49 \mathrm{~nm}$ voxel size, i.e. two voxels are used to define the smallest pore diameter). Out of these four connected pore volumes, three (EST27405-1, EST27405-2 and Tournemire-1) have the typical elongated morphology of cracks over a significant part of the pore volume; without these micro-cracks, the pore volumes are not connected from one surface to the other. The EST27405 core being made of non impregnated COx claystone, and the Tournemire-1 being epoxy-impregnated (impregnated mainly on its surface), it is concluded that sample preparation is bound to have yielded these micro-cracks, owing to drying shrinkage. On the whole, over five samples of the same claystone, imaged down to pores of $17 \mathrm{~nm}$ size, only one (the EST26095-2) has a connected pore volume, which is distinct of cracks (it may be assumed to be natural porosity, also present in the in situ-cored medium).

Although several of them are micro-cracked, the FIB/ SEM pore volumes have been used to predict macroscopic fluid permeability $K$ with Katz-Thompson equation (permeability to neutral fluids with respect to the clayey matter). The value of $K$ for the intact EST26095-2 sample $\left(K=5.4 \times 10^{-21} \mathrm{~m}^{2}\right)$ is significantly smaller than that of micro-cracked FIB/SEM samples (EST27405-1 and EST27405-2, $K=1.6 \times 10^{-20} \mathrm{~m}^{2}$ ). These values are all on the order of magnitude measured on centimetric plugs [8].

It is analyzed that FIB/SEM samples provide the biggest connected part of the pore volume (with pores bigger than 17-22 nm), which are useful for describing fluid transport at the macroscopic scale on the first order. Due to the limited volume of this pore network $(2.1 \%$ at most), and to its scarcity (one over five micrometric pore volumes is naturally connected), fluid transport of non-wetting fluids is bound to occur through a very limited proportion of discrete pathways (i.e. by a so-called fingering mechanism), rather than in a homogeneous manner through the whole centimetric plug volume [31].

Besides, in [31], we show that the porosity measured in clayey aggregates of the clay matrix with TEM imaging 
range between 10.2 and $25.2 \%$. For a claystone with $37-67 \%$ clay matrix and a total porosity on the order of $18 \%$, this explains only partly the location of all the pores: by a simple averaging rule (assuming that no other parts of the medium are porous), the clay content combined to the porosity at the TEM scale yields a porosity ranging between $3.8-16.9 \%$. Another potentially important source of pores, which has not been imaged herein, is that located at the interface between the non porous minerals (e.g. calcite, tectosilicates, pyrite). This will require further investigations.

In this context, where several micrometric pore volumes of the clay matrix of the COx (and Tournemire) claystones are available, this contribution investigates the prediction of GBP through COx and Tournemire claystones. Experimental validation is proposed with data obtained on centimetric-sized COx claystone samples [3]. The main method and results are recalled hereafter.

For GBP prediction, a number of assumptions is made regarding the flowpaths, i.e. either through the shortest pore path, or through the largest pore path, or through the most frequent pore size obtained by different methods, or through micro-cracks defined by their average width or by simulating the ingress of non-wetting fluid. Predicted GBP are analyzed and discussed, so that the most probable breakthrough paths are circumscribed.

\section{METHODS}

This contribution uses both FIB/SEM imaging and GBP experimental results. In this section, the FIB/SEM imaging technique and analysis are described, followed by the method for GBP assessment in the laboratory.

\subsection{FIB/SEM Imaging and Analysis}

Our FIB/SEM (FEI Strata DB235 instrument $^{T M}$ ) possesses a FIB, which first aim is to create a parallelepipoid out of the sample, by cutting a U-shaped hole from the polished surface (Fig. 1). The beam is along the vertical $y$ axis. The parallelepipoid is then imaged on its face perpendicular to the sample surface (in a $(x, y)$ plane) by an electron beam at an angle of $52^{\circ}$ to the vertical $y$ axis; the parallelepipoid is then cut by the ion beam, in order to remove a slice parallel to the imaged face, with a constant thickness, ranging from 10 to $50 \mathrm{~nm}$ (Tab. 1); the sample face is then imaged again (in a $(x, y)$ plane), prior to being cut by the ion beam. This procedure is automated (with the Slice and View ${ }^{T M}$ software package) in order to provide 200-300 2D grayscale images (an image stack) for each sample. While the imaged parallelepipoid sample is destroyed by the ion beam, the distance between two successive image is constant, which allows $3 \mathrm{D}$ image reconstruction.

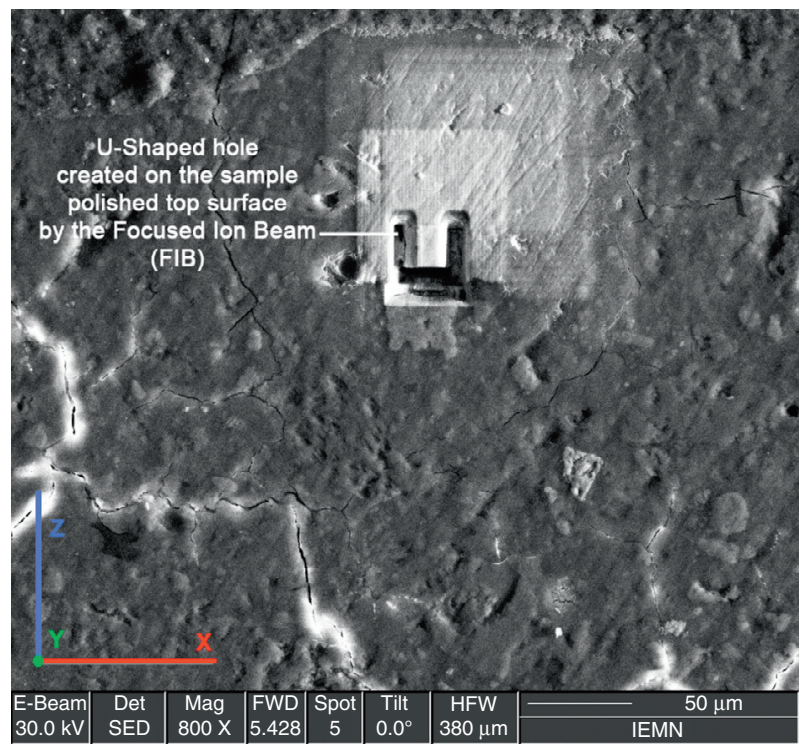

Figure 1

SEM image of the sample polished top surface (in the $(x, z)$ plane) after creation of the U-shaped hole by FIB. The isolated parallelepipoid is regularly sliced in a $(x, y)$ plane (by the FIB) and imaged (by the electron beam) at a 10-50 nm thickness until obtaining a 200-300 grayscale image stack.

\subsubsection{Image Processing}

Once the grayscale images are obtained, the aim is to isolate the pores (in black) from the rest (in white), i.e. to derive binary images, from which a 3D pore network can be reconstructed. The method described here is strictly identical to that used in [8], where further details are available.

To this purpose, the FIB/SEM images are:

- tilted in order to account for the $52^{\circ}$ angle of the electron beam with respect to the imaged $(x, y)$ plane,

- aligned and cropped to select areas strictly aligned along the $z$ axis (without translation along the $(x, y)$ plane).

A minimal filtering is then performed: the image background is removed (it is mainly the dark shadowing effects due to the bottom of the U-shaped hole), the vertical curtain artifacts are removed (with the FFT transform), and the Median Filter 3D is used with a 1.5 pixel size (to remove salt and pepper effects). Further, the histograms of all the images of the stack are normalized in order to span the whole grayscale range. Finally, segmentation (i.e. thresholding) is performed with each of the 17 algorithms available in the free software ImageJ. Discussion of the choice of the adequate segmentation algorithm is proposed in $[8,31]$.

All forthcoming analysis are performed on a single binary image stack (pores in black and solids in white) per sample, obtained with the Yen algorithm. 


\subsubsection{D Pore Network, Connectivity and lentification of Major Cracks}

Segmented image stacks are combined in FEI Avizo Stan$\operatorname{dard}^{T M}$ software. A 3D reconstruction tool (SurfaceGen or Surface Generate) is available to image the pore surface. Whenever a part of the pore volume has one dimension significantly smaller than the others (of at least one tenth smaller than the other in the $(x, y)$ plane), it is identified as a crack and its volume is selected by the Magic Wand tool in Avizo software. The Magic Wand tool selects all contiguous pixels to that selected; the 'all slices' option, which we use, expands the selection to as many contuguous voxels as there exists in the stack. Contiguous means that at least one pixel (or voxel) face is common with the other. Identified crack volumes are then considered as distinct objects from the rest of the pore network. This method is also used to determine the connected and non connected parts of the $3 \mathrm{D}$ pore volumes. Connectivity is determined between any two parallel sample end surfaces. When connectivity exists, it is observed consistently between the closest end surfaces. In the following, only the connected parts of the pore volumes are considered for GBP prediction.

\subsubsection{Sample Representativeness}

Each pore volume is assessed relatively to its representativeness towards the claystone microstructure, and most particularly towards its clay matrix. To this purpose, two complementary methods are used to determine the variability of porosity in any subset of the stack, depending on the subset size considered.

In both cases, the box counting method provides mean porosity values for any subset (or box) of size $L$. The box location is varied all over the $2 \mathrm{D}$ images, for the whole stack; $L$ is varied from a two voxel size to the entire sample size. This method also provides standard deviation, and the relative error $\operatorname{err}(L)$ (expressed in \%), defined as:

$$
\operatorname{err}(L)=100 \times \frac{\operatorname{std}(L)}{\phi_{\text {mean }}(L)}(\%)
$$

where $\operatorname{std}(L)$ is the standard deviation at a given box size $L$, and $\phi_{\text {mean }}(L)$ is the mean porosity (for the whole stack) determined at a given box size $L$.

The local porosity distribution $\phi$ is given for a box of size $L$, centered on a pixel of coordinates $x_{i}[16,32,33]$, by:

$$
\mu(\phi, L)=\frac{1}{m} \sum_{i=1}^{m} \delta\left(\phi-\phi\left(x_{i}, L\right)\right)
$$

where $m$ is the number of positions of the box of given size $L$, and $\delta(t)$ is the Dirac delta function. At given box size $L$, should this distribution display a single narrow peak centered on sample porosity (rather than a wide distribution), the pore space, at this scale, is considered to present a certain spatial homogeneity [16].

A full discussion of sample representativeness is proposed in $[8,31]$, where it is shown that our micrometric claystone volumes may be considered representative of the sole clay matrix (not of the macroscopic scale, which also comprises non porous grains of tectosilicates and carbonates, pyrite, and their interfaces).

In this contribution, we show relative error $\operatorname{err}(L)$ results for all the five COx claystone image stacks (Fig. 2a), and an example of local porosity distribution for EST26095-3 (Fig. 2b, not previously published in [8]). For the bigger box sizes, the relative error $\operatorname{err}(L)$ may remain on the order of $70-80 \%$ for Tournemire-1 and EST26095-1 samples, whereas it can go down below 20\% for EST27405-1 and EST27405-2; intermediary values on the order of $35 \%$ are obtained for EST26095-2 and EST26095-3. It is interesting to note that the bigger the sample volume, the bigger the relative error $\operatorname{err}(L)$. These results highlight the significant variability of porosity within the FIB/SEM samples, located within the sole clay matrix. It is a difficulty inherent to the imaging technique, which requires to image small sample volumes (of 27.8-553 $\mu \mathrm{m}^{3}$ ) in order to visualize small pore sizes (down to 17-22 nm). This justifies a statistical approach, whereby each sample is a realization of the clay matrix porosity.

As for the local porosity distribution of the EST26095-3 sample (Fig. 2b), no distinct pore peak exists for a small box size $L$ of $0.19 \mu \mathrm{m}$ : no sufficient homogeneity of the pore volume exists at this scale. For bigger box sizes $L$, on the order of 1.91 to $2.87 \mu \mathrm{m}$, a single peak is obtained. In such instance, a single average porosity exists, which is the signature of a certain homogeneity of the pore space. For a bigger box size $L$ of $4.78 \mu \mathrm{m}$, two peaks are observed, which are attributed to the presence of two distinct pore features. Indeed, this sample is made of a natural pore volume, which does not resemble cracks (first pore feature), mixed with a distinct micro-crack with one dimension significantly smaller than the others (second pore feature) [31]. The local porosity distribution provides a means to distinguish this micro-crack (at big box sizes) or to provide a single average porosity gathering all the distinct pore objects present down to $17-22 \mathrm{~nm}$ (i.e. a single peak at intermediary box sizes of 1.91-2.87 $\mu \mathrm{m})$.

\subsubsection{Pore Shape and Size Distribution (PSD)}

2D and 3D Continuous Pore Size Distribution (3D CPSD) are proposed by [34, 35], and used herein. Indeed, CPSD are based on the assumption that the complex pore network is a continuum, which may be invaded by a fluid as in MIP, yet not from the outer sample surfaces (as with MIP) 

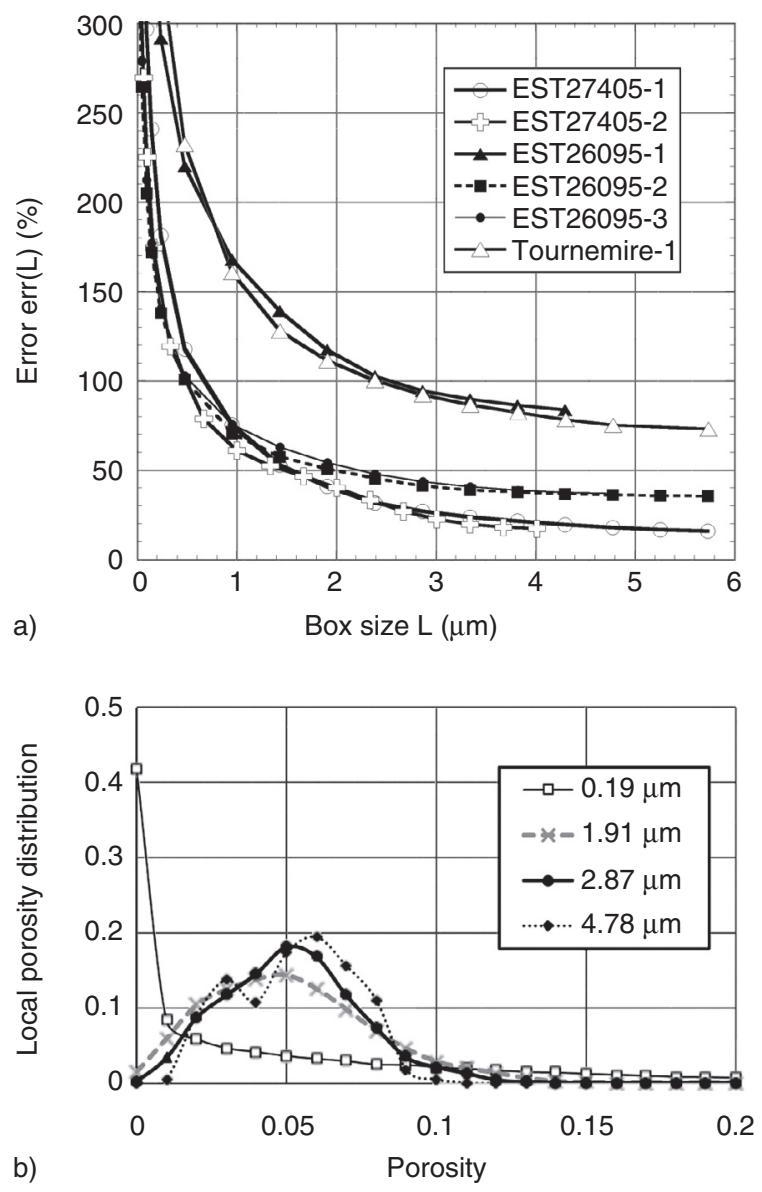

Figure 2

a) Relative error $\operatorname{err}(L)$ results for all the five COx claystone image stacks. (b) Local porosity distribution $\mu(\phi, L)$ for EST26095-3 (COx claystone).

but by gradual invasion from the widest zone in the pore volume. This resembles more the invasion mechanisms of nitrogen or $\mathrm{CO}_{2}$ within a dry porous medium. CPSD calculations progress by measuring the pore volume (respectively area in 2D) invaded by a smaller and smaller sphere (in 3D) or disk (in 2D). Pore sizes are quantified by the Euclidian distance to the nearest boundary, so that CPSD corresponds to the relative pore volume (respectively area in 2D) at a given sphere (respectively disk in 2D) size interval. In practice, 2D and 3D CPSD are performed by using the Beat plugin available at $\mathrm{ftp} / / / \mathrm{ftp}$. empa.ch/pub/empa/outgoing/BeatsRamsch/lib. This toolbox is also able to simulate the intrusion of a fluid (mercury) from one end surface of the sample to its parallel opposite end surface, by progressing through the $3 \mathrm{D}$ connected pore volume; this MIP simulation is used hereafter for comparison purposes.

\subsubsection{Skeletonization and Characterization of Pore Paths}

Skeletonization consists of thinning the pore volume to a minimum, i.e. down to lines of one voxel thickness. A skeleton is made of an assembly of nodes and segments (or branches), each segment being charaterized by an average pore diameter. The distribution of the average pore diameter over the whole skeleton is a method to quantify the PSD (Fig. 6). Several algorithms are able to provide a skeleton. In Avizo $^{T M}$, two such algorithms are available: the AutoSkeleton and the Centerline Tree [36, 37]. Contrarily to the AutoSkeleton, the Centerline Tree skeletonization algorithm provides a tree topology, without any loop.

When the tree-like skeleton is determined, each path between two end nodes is carefully identified by a recursive loop. Our method is derived from the connected-component analysis for graphs [38,39], combining a union-find and a recursive algorithm. This approach follows research findings by Lindquist et al. [40-43] on the 3D geometry of the pore space in rocks. In practice, after the identification of a first path, its end node is artificially removed from the skeleton used for the analysis, to ensure that the path is not identified twice. Also, in order to avoid that a path should be identified twice (in one direction and then the other), the start node is imposed to have a strictly smaller label number than the end node. Moreover, this procedure alone does not ensure that all identified paths are located between two parallel end surfaces, to ensure connectivity. This requires to validate the location of the start and end nodes of the paths (one on a given end surface, and the other on the opposite parallel surface). Once each connected path is identified by a set of node labels, we determine its length as the sum of the lengths of each branch of the path (located between two neighbouring nodes), its main orientation (as that of the vector formed by the start and end nodes of the path) and also its tortuosity [8]. From the path length distribution, the shortest path length is deduced by minimization. The whole method for the extraction of particular paths is coded through an in-house Fortran program.

Nota: Other approaches exist, which do not require any skeletonization prior to determining the connected pore paths [32, 44-46]. Comparison of these approaches with that chosen here, for its simplicity, will be the subject of future research.

\subsection{GBP Experiments}

The laboratory experiments used as a validation of our GBP predictions are detailed in $[3,5]$. They aim to reproduce the in situ loading and gas breakthrough conditions through initially water-saturated claystone. In brief, a centimetric-sized claystone sample (37 mm diameter, 10 to $30 \mathrm{~mm}$ height) is placed in a hydrostatic cell [1], and subjected to a confining pressure $P_{c}$ of 6 or $12 \mathrm{MPa}$ (smaller than or on the order of 


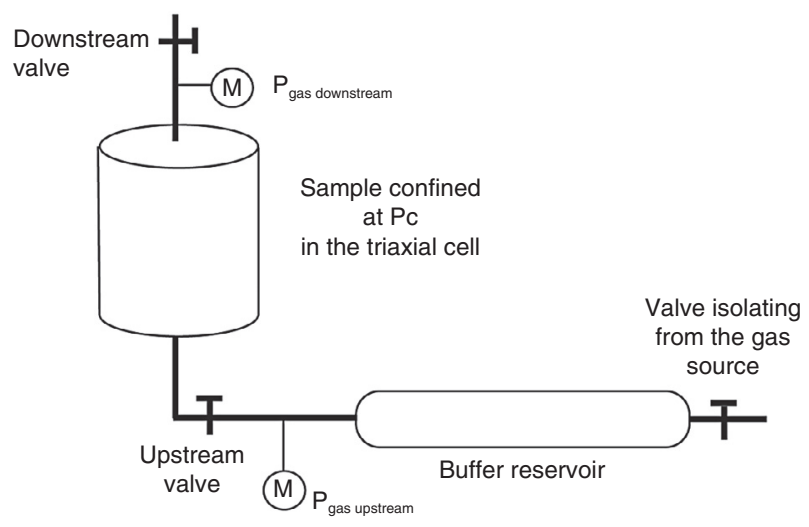

Figure 3

Configuration of the GBP experiment after sample water saturation, from [5]. Argon gas injection pressure is stabilized through an upstream buffer reservoir, and all measurements are performed on the sample downstream side, in a $2 \mathrm{cl}$ chamber closed by a valve, which is opened regularly (every 24-72 h) for GBP assessment.

in situ principal stress levels). It is injected with synthetic water (of in situ composition [47]) on its upstream side at $4 \mathrm{MPa}$ pressure, i.e. at the lithostatic water pressure. Full saturation is achieved when water permeability $K_{\text {water }}$ falls below $10^{-20}-10^{-21} \mathrm{~m}^{2}(1-10 \mathrm{nD})$, which is the expected permeability of undisturbed claystone.

Following water saturation, upstream pipes of the hydrostatic cell are emptied from water, while the sample is kept at a constant confinement $P_{c}=6$ or $12 \mathrm{MPa}$, in order to avoid its premature failure. The downstream chamber placed right after the sample is closed by a dedicated valve, and its pressure $P_{\text {downstream }}$ is recorded with a pressure transducer accurate to $\pm 100 \mathrm{~Pa}$ (Fig. 3). On the upstream side, argon gas pressure $P_{\text {upstream }}$ is increased very slowly, at a rate of 0.5-1 MPa per day. The upstream gas pressure is given by a pressure transducer accurate to $1 \mathrm{kPa}$. Gas detection on the downstream side is performed using both the downstream pressure transducer and a dedicated argon gas detector accurate to $\pm 10^{-7} \mathrm{~L} / \mathrm{s}$.

At constant imposed $P_{\text {upstream }}$ value, gas detection is performed every 24 to $72 \mathrm{~h}$, as follows: the downstream chamber valve is opened and gas is detected (or not) by placing the detector nozzle at about $5 \mathrm{~mm}$ from the valve opening. At first, gas appears discontinuously on the sample downstream side, and then, without changing the imposed upstream gas pressure, gas finally flows continuously, when it is given sufficient time. The pressure at which gas appears discontinuously, and then continuously, is the GBP.

After a first GBP test, the claystone sample is either subjected to a new water saturation phase for another GBP experiment (e.g. samples 1, 3 and 5), or it is dismounted.
This method alone does not ensure whether gas actually passes through the porous medium by dissolution and diffusion in pore water, or by capillarity. However, from first order calculations (see Aims and Scopes) and from separated measurements with a mix of gases (helium/argon), we show that dissolution and diffusion of gases do not explain discontinuous passage. Moreover, gas breakthrough occurs at a much lower pressure than that required to equilibrate the compressive stress state. The mechanism by pathway dilation is not a plausible explanation for breakthrough. Rather, in the following, capillarity is assumed to explain gas breakthrough.

\section{RESULTS AND ANALYSIS}

\subsection{GBP Laboratory Results}

Table 2 summarizes our main GBP results on COx claystone. At this stage, it is assumed that values on the same order would be obtained with Tournemire claystone. From Table 2, it is observed that several GBP experiments yield the same water permeability at saturation, whereas, for the same sample, GBP varies significantly from one experiment to the other, with values ranging from 1.45 to $5.3 \mathrm{MPa}$. For instance, for sample 5, although water permeability at saturation is very stable with values of $1.6-1.9 \times 10^{-20} \mathrm{~m}^{2}$, GBP varies from 2.2 to $3.6 \mathrm{MPa}$, i.e. it increases by $73 \%$. Also, GBP is greater with greater sample height, which is a partial explanation to its huge variations, at least when comparing different samples.

For a given sample, the huge variations in GBP are attributed to the gas breakthrough mechanism, i.e. to capillary fingering, with different pathways possibly followed from one test to the other. Greater GBP with greater sample height means that capillary fingering progresses with more difficulty when the overall path length increases.

In brief, all these observations are in good agreement with a capillary fingering phenomenon. Let determine how micrometric and connected pore volumes within the clay matrix (as given by FIB/SEM) may help further validate this interpretation, through the prediction of GBP by Laplace's law.

\subsection{FIB/SEM Micrometric Pore Volumes}

Figure 4 presents the 3D pore volumes of three COx claystone samples and of Tournemire- 1 sample. In green are represented the connected pore parts (at this scale), and the rest of the pore volume (which is disconnected at this scale) is either represented in red or in yellow. Table 1 shows that the total pore volumes identified at this scale (down to $17-22 \mathrm{~nm}$ pore size) are of only $1.70-5.90 \%$, for an expected 
TABLE 2

GBP results on five COx claystone samples, summarized from [5]

\begin{tabular}{|c|c|c|c|c|c|c|c|}
\hline Sample no. & Core EST & $\begin{array}{l}\text { Height } \mathrm{H} \\
\quad(\mathrm{mm})\end{array}$ & Initial state & $\begin{array}{c}P_{c} \\
(\mathrm{MPa})\end{array}$ & $\begin{array}{c}\text { Water } \\
\text { saturation } \\
\text { phase (days) }\end{array}$ & $\begin{array}{c}K_{\text {water }} \text { at } \\
\text { saturation } \\
\quad\left(\mathrm{m}^{2}\right)\end{array}$ & $\begin{array}{l}\text { GBP } \\
(\mathrm{MPa})\end{array}$ \\
\hline \multirow[t]{2}{*}{1} & 34386 & 10.9 & Macro-cracked & 12 & 16 & $9.34 \times 10^{-21}$ & 1.64 \\
\hline & & & & 12 & 63 & $9.34 \times 10^{-21}$ & 1.45 \\
\hline 2 & 34386 & 10.76 & Macro-cracked & 6 & 68 & $7.1-7.3 \times 10^{-21}$ & 2.25 \\
\hline \multirow[t]{2}{*}{3} & 44331 & 19.74 & Intact & 6 & 35 & $3.0 \times 10^{-20}$ & 4.5 \\
\hline & & & & 6 & 49 & $2.6 \times 10^{-20}$ & 4.38 \\
\hline 4 & 44140 & 30 & Intact & 6 & 134 & $6.9-7.4 \times 10^{-21}$ & $5.2-5.3$ \\
\hline \multirow[t]{4}{*}{5} & 44331 & 9.5 & Cracked & 6 & 30 & $1.9 \times 10^{-20}$ & 2.2 \\
\hline & & & & 6 & 13 & $1.6 \times 10^{-20}$ & 3.0 \\
\hline & & & & 6 & 96 & $1.8 \times 10^{-20}$ & 2.96 \\
\hline & & & & 6 & 50 & $1.7 \times 10^{-20}$ & 3.6 \\
\hline
\end{tabular}

$18 \% \pm 4$ at the macroscopic scale for COx claystone and $8 \% \pm 2$ for Tournemire. We have explained earlier (see Aims and Scopes) that such limited porosity down to $17-22 \mathrm{~nm}$ may be attributed to the presence of a significant amount of pores below $17 \mathrm{~nm}$ (imaged by TEM) [8] and of pores located at the interface between the clay matrix and non porous aggregates. The connected pore volumes of our FIB/ SEM samples are even smaller, with values ranging from $0.68-2.10 \%$. However, their geometry is complex enough to justify different possible migration modes to predict gas breakthrough, as follows.

\subsection{Predictions of GBP}

The following assumptions are made (on a first order prediction basis):

- the interaction of water with the clay aggregates (due to hydration or swelling) is not taken into account;

- to account for GBP, the connectivity of the micrometric pore volumes given by FIB/SEM is assumed representative of the macroscopic behavior, although located solely within the clay matrix (i.e. within clayey solids mixed with sub-micrometric non porous grains);

- the breakthrough mechanism is due to visco-capillary flow, i.e. it is describable by Laplace's law for the interface between air/water (Eq. 1).

Several subsequent assumptions are made to describe simply the gas breakthrough through a 3D pore volume, without requiring 3D numerical simulations. Firstly, we only use the data provided by the skeleton of the connected pore volume, in terms of shortest path or largest path, or of most frequent pore size. This means that results in this contribution will be slightly different from [8], where we used the whole pore volume (connected and non connected). Secondly, we propose a prediction based on pore entry size, as determined by MIP simulations. Finally, we propose to deduce GBP rather from the characteristic size of cracks, which are identified and separated from the rest of the pore network, i.e. by using median crack widths.

\subsubsection{From the Shortest Path - After Skeletonization}

In this sub-section, we assume that gas passes through the shortest pore path, so that the determining pore diameter is the smallest pore throat along the shortest pore path. The shortest pore path is determined for the skeleton of the four connected pore volumes, as given by the centerline tree algorithm. This algorithm is preferred because it provides a more realistic skeleton for fluid movements, without loops, for the considered pore volume. From the pore size distribution along the shortest path (Fig. 5a), we determine the pore throat as the minimum pore size value for each sample (Tab. 3). Figure 5a shows how hugely varying the pore size distribution is along the shortest path. We also observe that the smallest pore size is equivalent to the smallest pore size available with FIB/SEM, i.e. between 17-26 nm, and that it is reached several times along the path, i.e. the gas passage is made difficult several times along its progression through this shortest path. These are flow constrictions representing 'bottlenecks' for gas flow. 


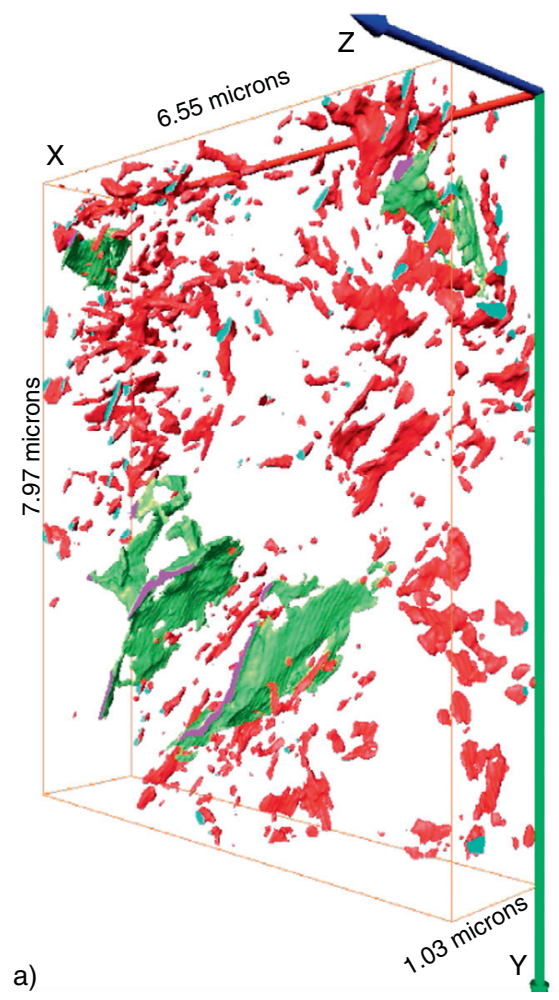

b)
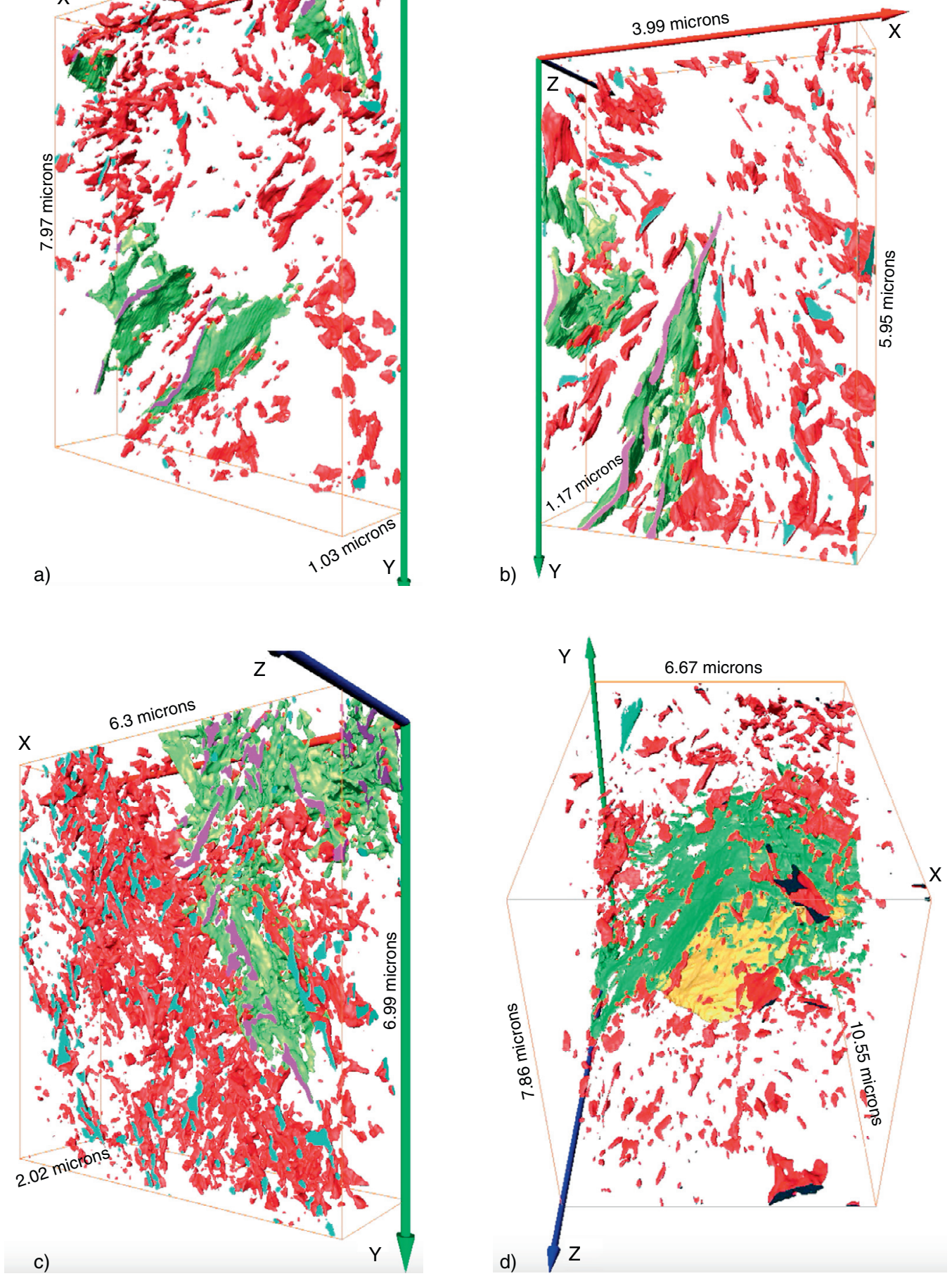

Figure 4

3D pore volume of a) EST27405-1, b) EST27405-2, c) EST26095-2 COx claystone samples, and d). Tournemire-1 sample. In red are the non connected and non crack-like pores - these are likely to be connected by micro- and small meso-pores below the resolution of the FIB/SEM device; in green, the connected porosity between the end surfaces perpendicular to the $Z$-axis; in yellow and blue-green are the crack-like pores (Tournemire-1 sample only). 

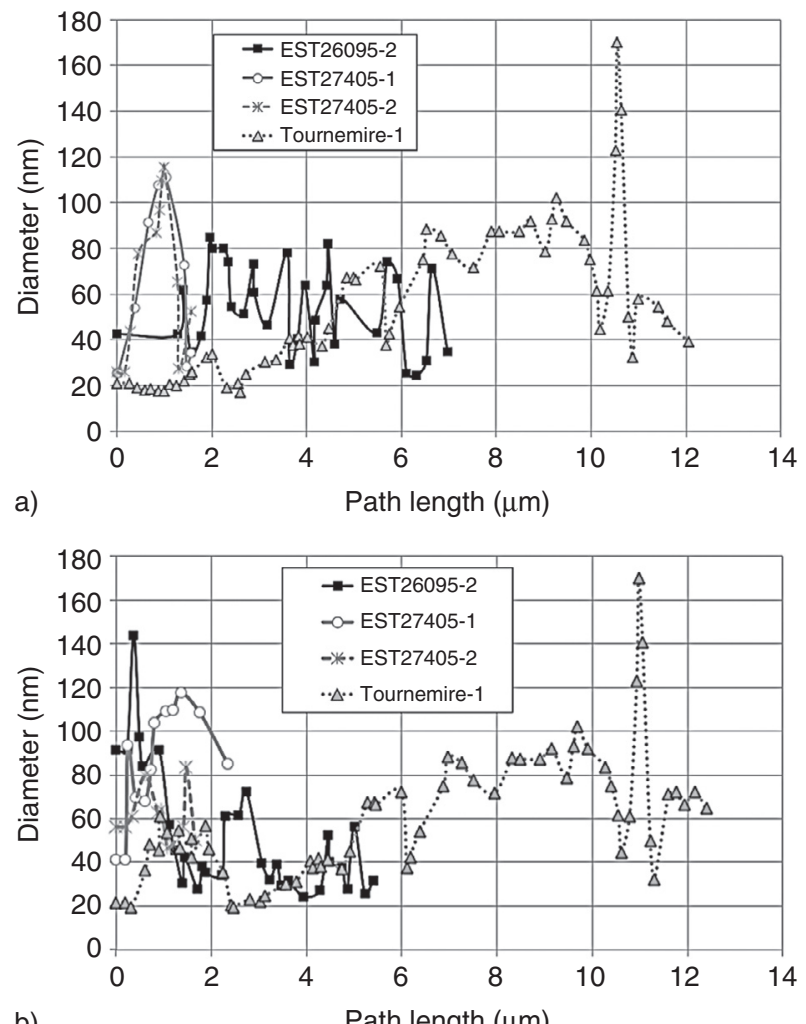

b)

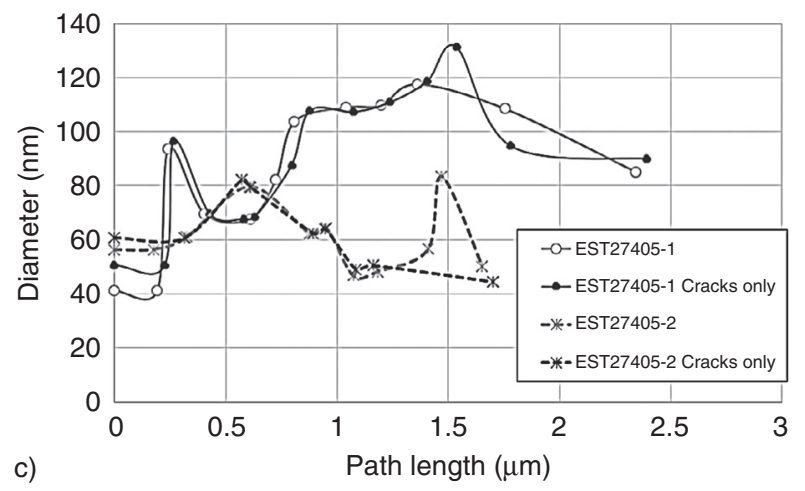

Figure 5

For all four connected claystone samples, distribution of pore diameters along a) the shortest path or b) the largest path; c): along the largest path, but limited to micro-cracked EST27405 samples, presented when taking the cracks into account (or not).

From these smallest pore throat values along the shortest paths, GBP is predicted (Tab. 3), and clearly over-estimated, with values ranging from 11.2 to $17.1 \mathrm{MPa}$, when compared to the experimental GBP values (Tab. 2). If all assumptions taken are correct, this means that gas does not pass through the shortest connected path, i.e. it passes through larger pores than $17-26 \mathrm{~nm}$.
TABLE 3

Pore throat diameter and predicted GBP along the shortest path

\begin{tabular}{c|c|c}
\hline Sample & $\begin{array}{c}\text { Pore throat diameter } \\
(\mathrm{nm})\end{array}$ & $\begin{array}{c}\text { Predicted breakthrough } \\
\text { pressure (MPa) }\end{array}$ \\
\hline EST27405-1 & 19.38 & 15.02 \\
\hline EST27405-2 & 25.92 & 11.23 \\
\hline EST26095-2 & 24.25 & 12.00 \\
\hline Tournemire-1 & 16.97 & 17.15 \\
\hline
\end{tabular}

TABLE 4

Pore throat diameter and predicted GBP along the path with the largest pore throat

\begin{tabular}{c|c|c}
\hline Sample & $\begin{array}{c}\text { Pore throat diameter } \\
(\mathrm{nm})\end{array}$ & $\begin{array}{c}\text { Predicted breakthrough } \\
\text { pressure (MPa) }\end{array}$ \\
\hline EST27405-1 & 41.27 & 7.05 \\
\hline EST27405-2 & 46.82 & 6.22 \\
\hline EST26095-2 & 24.39 & 11.93 \\
\hline Tournemire-1 & 19.32 & 15.06 \\
\hline
\end{tabular}

\subsubsection{From the Largest Path - After Skeletonization}

An alternative is that gas does not pass through the shortest path, but through the largest, though longer, connected path between two parallel end surfaces at the micrometric scale (Fig. 5b). Except for the Tournemire-1 and EST26095-2 samples, we observe that the smallest pore diameter along the largest path is, as expected, bigger than the smallest pore size available with FIB/SEM (i.e. bigger than 17-22 nm) (Tab. 4). For the two samples EST27405-1 and EST27405-2, the largest pore path is hardly affected when taking into account the whole connected pore volume or only its crack-like part (Fig. 5c). It means that the largest pathway connection for these samples occurs through their micro-cracks.

On the whole, this second assumption provides smaller GBP than when assuming a passage through the shortest pore path, as GBP values now range between 6.22-15.06 MPa. However, this is still over-estimating GBP when comparing with macroscopic experimental values (Tab. 2).

\subsubsection{From PSD Given by Skeletonization}

The peak pore size is the most frequent pore size encountered in the pore network. If gas is assumed to try and progress on several fronts at a time, i.e. through as many pathways as possible (and not only through the largest or the shortest), a realistic assumption is that gas passes mainly 
TABLE 5

Predicted GBP using the PSD processed after two different skeletonizations of the connected pore network

\begin{tabular}{|c|c|c|}
\hline Sample & $\begin{array}{l}\text { Peak pore diameter } \\
\qquad(\mathrm{nm})\end{array}$ & $\begin{array}{l}\text { Predicted breakthrough } \\
\text { pressure }(\mathrm{MPa})\end{array}$ \\
\hline \multicolumn{3}{|c|}{ Auto skeleton } \\
\hline EST27405-1 & 30 & 9.7 \\
\hline EST27405-2 & 90 & 3.23 \\
\hline EST26095-2 & 70 & 4.16 \\
\hline Tournemire-1 & $50 ; 60$ & $5.82 ; 4.85$ \\
\hline \multicolumn{3}{|c|}{ Centerline tree } \\
\hline EST27405-1 & $30 ; 40 ; 50$ & $9.7 ; 7.28 ; 5.82$ \\
\hline EST27405-2 & 90 & 3.23 \\
\hline EST26095-2 & 60 & 4.85 \\
\hline Tournemire-1 & 70 & 4.16 \\
\hline
\end{tabular}

through the most frequent pore size. With this assumption, the two available skeletons have been determined, because they provide slightly different estimations. These are readily observed on the PSD defined as the distribution of the average pore diameters on each skeleton segment (Fig. 6). With the skeleton given by the autoskeleton algorithm, the GBP predictions range between 3.23 and 9.7 $\mathrm{MPa}$ (Tab. 5), which is only partly over-estimating it when compared to experimental macroscopic values (Tab. 2). With the centerline tree skeletonization, smaller or equivalent values are predicted for GBP, when compared to the use of the autoskeleton (Tab. 5).

With both skeletons, we conclude that we have found a plausible GBP prediction for both COx claystone cores, and for the Tournemire claystone too. For the EST27405 core, breakthrough rather occurs through the EST27405-2 sample (with a predicted $\mathrm{GBP}=3.23 \mathrm{MPa}$ ) rather than through the EST27405-1 one (predicted GBP = 5.82-9.7 MPa). For the EST26095 core, the GBP value is of 4.16-4.85 MPa, and for Tournemire-1 the value is as low as $4.16 \mathrm{MPa}$, i.e. both are within the measured range for $\mathrm{COx}$ claystone. This means that it is plausible that gas migrates by capillarity through the natural connected pore volume identified by FIB/SEM, although it is located within the clay matrix, and of a few microns size.

However, while assuming that gas passes through a multitude of pathways (and not only through the largest or the shortest) may be relatively adequate, this method presents several limitations. Firstly, as the largest pore path passes through a smallest pore diameter of about $19.3-46.8 \mathrm{~nm}$, any other path requires the passage of gas through smaller pores (than 19.3-46.8 nm), so that the use of the most frequent pore diameter is not realistic. Indeed, there is
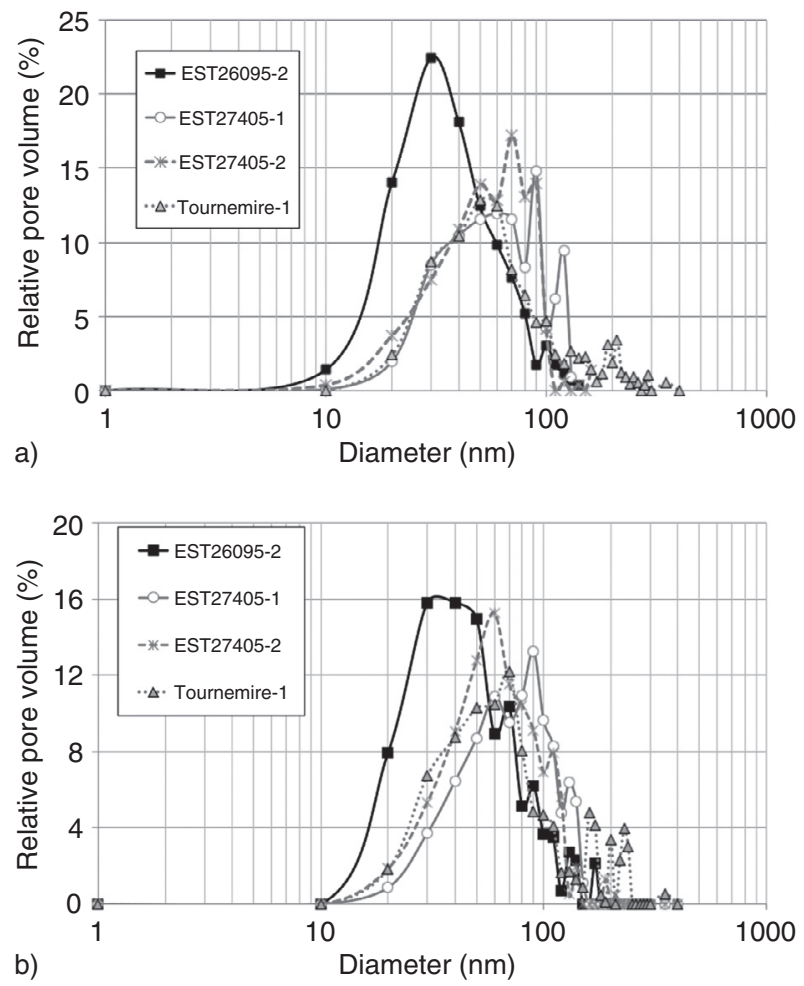

Figure 6

For all four connected claystone samples, Pore Size Distributions defined as the distribution of average pore diameters of all the segments, after skeletonization obtained a) by the Auto Skeleton method or b) by the Centerline Tree algorithm.

no reason for it to be the smallest pore diameter of any of the paths followed. Secondly, using the skeleton to derive PSD requires to simplify the connected pore volume. Let propose GBP predictions without resorting to a skeleton.

\subsubsection{Using Crack Widths as Determined from 2D and 3D CPSD}

The simplest idea is to use the 2D and 3D CPSD (Fig. 7) and assume that gas migrates through the most frequent pore size (i.e. through the peak pore size of these distributions) (Tab. 6). In particular, in 2D, the CPSD reflects the crack widths, which are visible in the $(x, y)$ planes of the 2D binary images. In such instance, the peak pore sizes are close to the average crack widths determined manually from several images, and as the geometrical tortuosity is 1 (cracks are straight paths), using a peak pore size may be considered a correct assumption.

In particular, for EST27405-1, the peak pore size (and average crack width) is of $90 \mathrm{~nm}$, whereas it is of $80 \mathrm{~nm}$ for the EST27405-2 sample, and an identical $90 \mathrm{~nm}$ for Tournemire-1 sample. For these connected volumes, the peak 

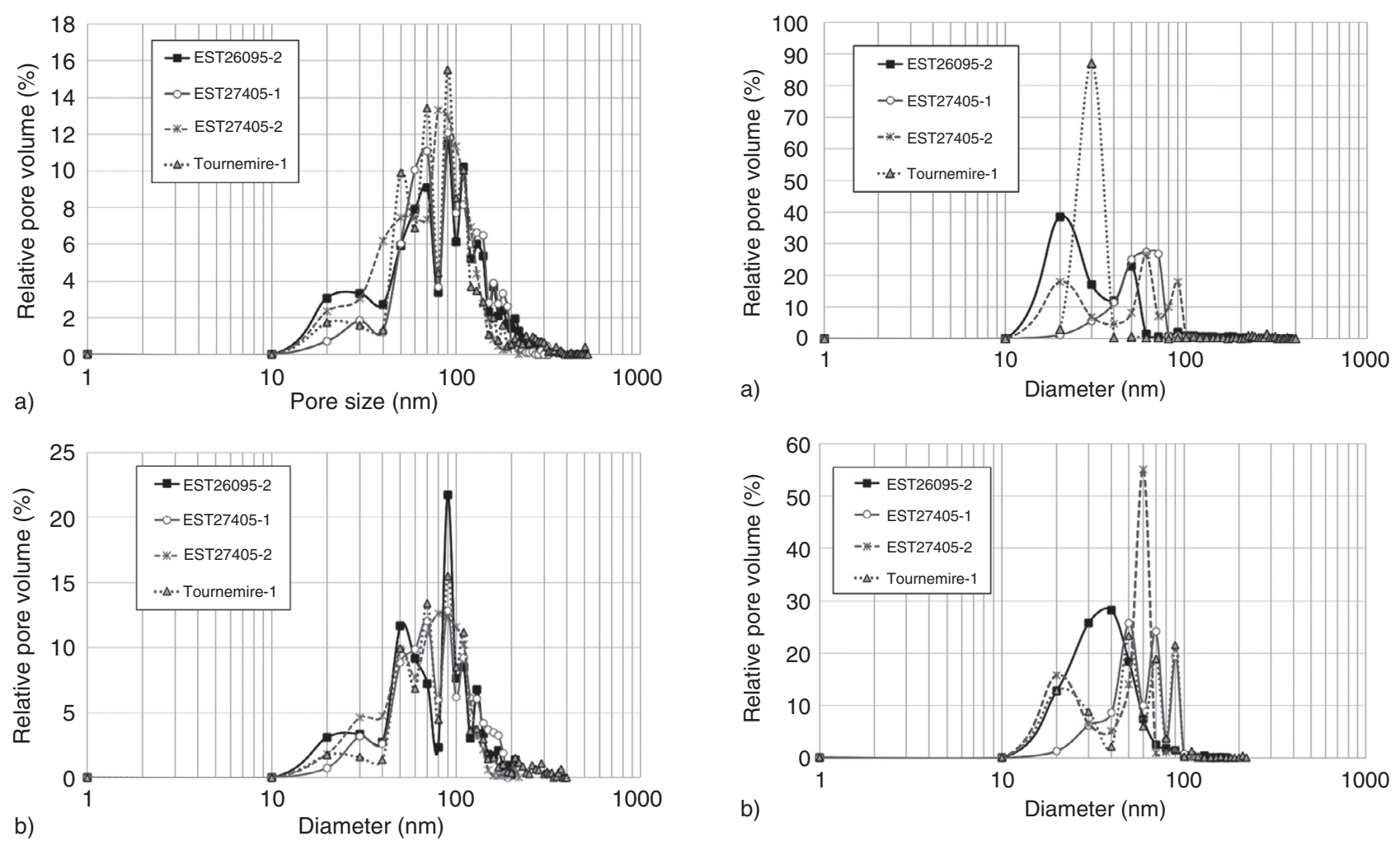

Figure 7

PSD given by a) the 2D CPSD method or b) the 3D CPSD method.

TABLE 6

Predicted GBP using the PPS from the 2D/3D CPSD

\begin{tabular}{c|c|c}
\hline Sample & $\begin{array}{c}\text { Peak pore diameter } \\
(\mathrm{nm})\end{array}$ & $\begin{array}{c}\text { Predicted breakthrough } \\
\text { pressure (MPa) }\end{array}$ \\
\hline EST27405-1 & 90 & 3.23 \\
\hline EST27405-2 & 80 & 3.64 \\
\hline EST26095-2 & 90 & 3.23 \\
\hline Tournemire-1 & 90 & 3.23 \\
\hline
\end{tabular}

skeleton, this method does not ensure that single paths are followed, i.e. it is not physically realistic.

\subsubsection{Using the Peak Pore Size Given by MIP Simulations}

Let try a more physical method, which accounts for the progression of gas through the porous medium from an entry surface; in particular, this method considers the succession of smaller or larger pores as the use of a skeleton and its associated paths did.

values are identical when using the 3D CPSD instead of the 2D. For the EST26095-2 sample however, the peak pore size given by CPSD is also of $90 \mathrm{~nm}$, although its connected pore volume is not crack-like. In this case, the use of actual paths instead of peak pore sizes would be more adequate to describe gas breakthrough, and the sole $90 \mathrm{~nm}$ peak pore size may not be a reliable way to determine the main gas pathway (tortuosity is significantly greater than 1 , contrarily to cracks).

With these peak pore sizes, GBP is predicted consistently as plausible, whatever the sample considered, with values of 3.23-3.64 MPa. However, as with PSD derived from the

Mercury is a non wetting fluid (with a contact angle generally of $130^{\circ}$ ), just as gas is, when trying to migrate through the water-wet solid. The Beat plugin available in ImageJ provides 3D simulation of mercury intrusion through the connected pore volumes (without any use of a skeleton), either from the bottom end surface (Fig. 8a) or along the top end surface (Fig. 8b). For a given sample, the variations in MIP simulations between the top and bottom end surfaces is related to the way the fluid progresses, from the chosen surface and through the complex 3D pore network, through 
TABLE 7

Predicted GBP using the PPS from MIP simulations (entry from the top surface perpendicular to the $x$ axis, or from the top surface perpendicular to the $z$ axis) of the connected pore network

MIP 1: from the bottom surface perpendicular to the $z$ axis (EST27405) or $x$ axis (Tournemire-1)

\begin{tabular}{c|c|c}
\hline EST27405-1 & $50 ; 60 ; 70$ & $5.82 ; 4.16 ; 3.23$ \\
\hline EST27405-2 & 60 & 4.85 \\
\hline EST26095-2 & 20 & 14.55 \\
\hline Tournemire-1 & 30 & 9.7 \\
\hline
\end{tabular}

MIP 2: from the top surface perpendicular to the $z$ axis (EST27405) or $x$ axis (Tournemire-1)

\begin{tabular}{c|c|c}
\hline EST27405-1 & $50 ; 70 ; 90$ & $5.82 ; 4.16 ; 3.23$ \\
\hline EST27405-2 & 60 & 4.85 \\
\hline EST26095-2 & 40 & 7.28 \\
\hline Tournemire-1 & $50 ; 70 ; 90$ & $5.82 ; 4.16 ; 3.23$ \\
\hline
\end{tabular}

to the other end; it is impacted by the succession of pores encountered along this progression.

With this method, predicted GBP range between an acceptable $3.23 \mathrm{MPa}$ and an over-estimated $14.55 \mathrm{MPa}$ (Tab. 7). No prediction is within the acceptable range (given by macroscopic experiments) for the EST26095-2 sample ( $\mathrm{GBP}=7.28-14.55 \mathrm{MPa}$ ), but gas breakthrough is plausible by capillarity through both EST27405-1 and EST27405-2 $(\mathrm{GBP}=3.23-4.85 \mathrm{MPa}$ are acceptable $)$, and through the Tournemire-1 sample (GBP = 3.23-4.16 MPa are acceptable).

It is concluded that with this most plausible gas migration mode (similar to mercury intrusion), gas breakthrough is predicted for the EST27405 core (and for Tournemire claystone) by using micrometric pore volumes located in the clay matrix and given by FIB/SEM, which are micro-cracked. On the opposite, if non micro-cracked EST26095-2 sample is representative of the macroscopic scale, it does not allow gas breakthrough as measured in the laboratory. Rather, for EST26095, breakthrough with values similar to those presented in Table 2 is bound to occur through larger pores, and very possibly through micro-cracks. In situ, these are bound to be present in the EDZ, despite claystone selfsealing. On the opposite, if capillary digitation is the proper mechanism for gas breakthrough, intact $\mathrm{COx}$ claystone has a GBP ranging between 7.3-14.5 $\mathrm{MPa}$, when using the naturally connected pore volume of EST26095-2.

\section{CONCLUSION}

This contribution predicts macroscopic GBP experimental results by using micrometric and connected pore volumes of the clay matrix of COx claystone and of Tournemire claystone. To this purpose, a set of assumptions is necessary:

- the interaction of water with the clay aggregates is not taken into account;

- to account for GBP, the micrometric pore volumes given by FIB/SEM are representative of the macroscopic behavior, although located solely within the clay matrix;

- the breakthrough mechanism is due to visco-capillary flow, i.e. it is describable by Laplace's law for the interface between air/water.

By using data from the skeletons derived from the connected pore volumes, we show that plausible GBP predictions by capillarity require that the gas does not pass solely through the shortest pore path, nor through the sole largest pore path, but through a multitude of pathways. Although providing realistic GBP predictions (3.23-4.85 MPa for both COx claystone cores) when resorting to the most frequent pore size, this does not reproduce the progression through a path within the material, so that this is not considered physically relevant.

Without simplifying the pore volumes with skeletons, 3D simulations of non wetting fluid intrusion is performed from any of the connected end surfaces of the samples. In such instance, which is considered the most physically plausible, GBP is adequately predicted by capillarity for the COx EST27405 core and for the Tournemire-1 claystone. In both cases, the main pathways are crack-like. On the opposite, for the naturally connected pore volume of the EST26095-2 sample, the capillary digitation mechanism predicts a GBP ranging between 7.3-14.5 MPa. This means that none of our GBP experiments on 1-3 cm thick samples have been performed on intact matter. Indeed, sample preparation to such small thickness is bound to create micro-cracks in the medium.

This also means that for these claystones, if the capillary fingering mechanism is the proper breakthrough mechanism, the only way to account for the low GBP values measured at the macroscopic scale is to accept the presence of microcracks. An alternative to sufficiently big pores (that microcracks represent) would be the interfaces between the clay matrix and non porous grains. Identifying the latter would require to benefit from a $3 \mathrm{D}$ imaging device allowing to span greater volumes than our FIB/SEM, and yet smaller pore sizes than XRT, i.e. pore sizes ranging between $50-700 \mathrm{~nm}$. This is being rendered possible by the currently developed FIB/SEM instruments. This will hopefully be the subject of future research.

Another conclusion of this contribution is that gas passage through a liquid-saturated claystone (intact or microcracked) occurs through a limited amount of pathways, and not in a homogeneous manner through the whole volume, as standard macroscopic finite element models would represent it. This mechanism is usually termed capillary fingering. 


\section{ACKNOWLEDGMENTS}

We acknowledge funding by NEEDS MIPOR (Grand Défi Inter-Disciplinaire Nucléaire: Énergie, Environnement, Déchets, Société - MIlieux POReux, funded by CNRS, CEA, EDF, ANDRA, AREVA, IRSN, BRGM, France) in 2014/2015, under the DiphLBM2 project label (kindly coordinated by M. Dimitrowska, IRSN).

The authors are most grateful to L.M. Keller for making the Beat plugin (ImageJ) available to the scientific community.

\section{REFERENCES}

1 Davy C.A., Skoczylas F., Barnichon J.-D., Lebon P. (2007) Permeability of macro-cracked argillite under confinement: Gas and water testing, Physics and Chemistry of the Earth 32, 8-14, 667-680.

2 Davy C.A. (2012) Gas migration through watersaturated argillite: a synthesis of experiments performed at LML. Presentation in GL Transfert de gaz, January.

3 Davy C.A. (2012) Self-sealing and self-healing of COx claystone. Clays in Natural and Engineered Barriers for Radioactive Waste Confinement, 5th International Meeting, October.

4 ANDRA (Agence Nationale pour la gestion des Déchets RAdioactifs). (2005) Dossier 2005 Argile : évaluation de la faisabilité du stockage géologique en formation argileuse profonde - rapport de synthèse. Available at:http.//www.andra.fr.

5 Song Y., Davy C.A., Talandier J., Skoczylas F. (2016) On the nature of gas migration through COx claystone, Journal of Contaminant Hydrology, submitted.

6 Keller L.M., Holzer L., Wepf R., Gasser P. (2011) 3D geometry and topology of pore pathways in Opalinus clay: Implications for mass transport, Applied Clay Science 52, 85-95.

7 Keller L.M., Schuetz P., Erni R., Rossell M.D., Lucas F., Lucas M., Gasser P., Holzer L. (2013) Characterization of multi-scale microstructural features in Opalinus clay, Microporous and Mesoporous Materials 170, 83-94.

8 Song Y., Davy C.A., Troadec D., Blanchenet A.-M., Skoczylas F., Talandier J., Robinet J.C. (2015) Multiscale pore structure of COx claystone: Towards the prediction of fluid transport, Marine and Petroleum Geology 65, 63-85.

9 Desbois G., Urai J.L., Kukla P.A. (2009) Morphology of the pore space in claystones - evidence from BIB/FIB ion beam sectioning and cryo-SEM observations, E-Earth 4, 15-22.

10 Desbois G., Urai J.L., Pérez-Willard F., Radi Z., van Offern S., Burkart I., Kukla P.A., Wollenberg U. (2013) Argon broad ion beam tomography in a cryogenic scanning electron microscope: a novel tool for the investigation of representative microstructures in sedimentary rocks containing pore fluid, Journal of Microscopy 249, 3, 215-235.

11 Desbois G., Urai J.L., Hemes S., Brassines S., De Craen M., Sillen X. (2014) Nanometer-scale pore fluid distribution and drying damage in preserved clay cores from belgian clay formations inferred by BIB-cryo-SEM, Engineering Geology 179, 117-131.

12 Hemes S., Desbois G., Urai J.L., Schröppel B., Schwarz J.O. (2015) Multi-scale characterization of porosity in Boom Clay (HADES-level, Mol, Belgium) using a combination of X-ray $\mu$-CT, 2D BIB-SEM and FIB-SEM tomography, Microporous \& Mesoporous Materials 208, 1-20.
13 Houben M.E., Desbois G., Urai J.L. (2013) Pore morphology and distribution in the Shaly facies of Opalinus clay (Mont Terri, Switzerland): Insights from representative 2D BIBSEM investigations on $\mathrm{mm}$ to $\mathrm{nm}$ scale, Applied Clay Science 71, 82-97.

14 Houben M.E., Desbois G., Urai J.L. (2014) A comparative study of representative 2D microstructures in Shaly and Sandy facies of Opalinus Clay (Mont Terri, Switzerland) inferred from BIB-SEM and MIP methods, Marine and Petroleum Engineering 49, 143-161.

15 Keller L.M., Holzer L., Wepf R., Gasser P., Münch B., Marschall P. (2011) On the application of focused ion beam nanotomography in characterizing the 3D pore space geometry of Opalinus clay, Physics and Chemistry of the Earth, Parts $A / B / C$ 36, 17-18, 1539-1544.

16 Keller L.M., Holzer L., Schuetz P., Gasser P. (2013) Pore space relevant for gas permeability in Opalinus clay: Statistical analysis of homogeneity, percolation, and representative volume element, Journal of Geophysical Research: Solid Earth 118, 2799-2812.

17 Robinet J.C., Sardini P., Coelho D., Parneix J.C., Prêt D., Sammartino S., Boller E., Altmann S. (2012) Effects of mineral distribution at mesoscopic scale on solute diffusion in a clayrich rock: Example of the Callovo-Oxfordian mudstone (Bure, France), Water Resources Research 48, W05554, 1-17.

18 Yven B., Sammartino S., Geraud Y., Homand F., Villieras F. (2007) Mineralogy, texture and porosity of Callovo-Oxfordien argillites of the Meuse/Haute-Marne region (eastern Paris basin), Mémoires de la Société Géologique de France 178, 73-90.

19 IUPAC (International Union of Pure and Applied Chemistry). (1995) Recommendations, Pure Appl. Chem. 66, 1739.

20 Duveau G., Jahad S.M., Davy C.A., Skoczylas F., Shao J.-F., Talandier J., Granet S. (2011) Gas entry through watersaturated argillite: experimental and numerical approaches. Proceedings of the international conference 45th US Rock Mechanics Geomechanics Symposium ARMA, San Francisco, USA, 26-29th, June.

21 Egermann P., Lombard J.-M., Bretonnier P. (2006) A fast and accurate method to measure threshold capillary pressure of cap rocks under representative conditions. Paper SCA A46, 2006 SCA International Symposium, Trondheim, Sept. 18-22.

22 Hildenbrand A., Schlömer S., Krooss B.M. (2002) Gas breakthrough experiments on fine-grained sedimentary rocks, Geofluids 2, 1, 3-23.

23 Horseman S.T., Harrington J.F., Sellin P. (1999) Gas migration in clay barriers, Engineering Geology 54, 139-149.

24 Amann-Hildenbrand A., Ghanizadeh A., Krooss B.M. (2012) Transport properties of unconventional gas systems, Marine and Petroleum Geology 31, 1, 90-99.

25 Cuss R., Harrington J. (2012) Evidence for dilatancy during the onset of gas flow. Presentation at the GL Transfert de gaz annual meeting, FORGE WP 4.1.1 E_ect of stress field and mechanical deformation on permeability and fracture selfsealing, January 26th.

26 Cuss R., Harrington J., Giot R., Auvray C. (2014) Experimental observations of mechanical dilation at the onset of gas flow in Callovo-Oxfordian claystone. Clays in Natural and Engineered Barriers for Radioactive Waste Confinement. Geological Society Special Publications: London, United Kingdom, Geological Society of London. 
27 Harrington J.F., de la Vaissière R., Noy D.J., Cuss R.J., Talandier J. (2012) Gas flow in Callovo-Oxfordian claystone (COx): results from laboratory and field-scale measurements, Mineralogical Magazine 76, 8, 3303-3318

28 Marschall P., Horseman S., Gimmi Th. (2005) Characterisation of gas transport properties of the Opalinus clay, a potential host rock formation for radioactive waste disposal, Oil \& Gas Science and Technology 60, 1, 121-139.

29 Zhang C.L., Rothfuchs T. (2008) Damage and sealing of clay rocks detected by measurements of gas permeability, Physics and Chemistry of the Earth 33, S363-S373.

30 Gerard P., Harrington J.F., Charlier R., Collin F. (2014) Modelling of localised gas preferential pathways in claystone, International Journal of Rock Mechanics and Mining Sciences 67, 104-114.

31 Song Y., Davy C.A., Troadec D., Bertier P., Skoczylas F. (2016) Understanding fluid transport through claystones from their 3D nanoscopic pore network, Microporous and Mesoporous Materials, under revisions.

32 Biswal B., Manwart C., Hilfer R. (1998) Three-dimensional local porosity analysis of porous media, Physica $A \mathbf{2 5 5}$, 221-241.

33 Hilfer R. (1991) Geometric and dielectric characterization of porous media, Phys. Rev. B 44, 60.

34 Holzer L., Münch B., Rizzi M., Wepf R., Marschall P., Graule T. (2010) 3D-microstructure analysis of hydrated bentonite with cryo-stabilized pore water, Applied Clay Science 47, 3, 330-342.

35 Münch B., Holzer L. (2008) Contradicting geometrical concepts in pore size analysis attained with electron microscopy and mercury intrusion, Journal of the American Ceramic Society 91, 12, 4059-4067.

36 Sato M., Bitter I., Bender M.A., Kaufman A.E., Nakajima M. (2000) TEASAR: Tree-structure extraction algorithm for accurate and robust skeletons. Computer Graphics and Applications, Proceedings. The Eighth Pacific Conference, pp. 281-449, IEEE.

37 Bitter I., Wan M., Kaufman A., Dachille F., Kreeger K., Liang Z., Wax M. (2004) Centerline and tree branch skeleton determination for virtual objects, US patent $n$. US20040109603 A.
38 Rosenfeld A., Pfaltz J.L. (1966) Sequential operations in digital picture processing, Journal of the Association for Computing Machinery 13, 4, 471-494.

39 Suryanarayanan S., Gopinath A., Mallya Y., Shriram K.S., Joshi M. (2006) Automatic tracking of neuro vascular tree paths. Medical Imaging 2006: Image Processing, Reinhardt J.M., Pluim J.P.W. (eds), Proceedings of the SPIE, Vol. 6144, $61444 \mathrm{~N}$.

40 Lindquist W.B., Lee S.M., Coker D., Jones K., Spanne P. (1996) Medial axis analysis of void structure in threedimensional tomographic images of porous media, J. Geophys. Res. 101B, 8297-8310.

41 Lindquist W.B., Venkatarangan A. (199) Investigating 3D geometry of porous media from high resolution images, Phys. Chem. Earth (A) 25, 593-599.

42 Lindquist W.B., Venkatarangan A., Dunsmuir J., Wong T.-f. (2000) Pore and throat size distributions measured from sychrotron X-ray tomographic images of Fontainebleau sandstones, J. Geophys. Research 105B, 21508-21528.

43 Lindquist W.B. (2002) Network flow model studies and 3D pore structure, Contemp. Math. 295, 355-366.

44 Hunt A., Ewing R. (2009) Percolation Theory for Flow in Porous Media, volume 771, Lect. Notes in Phys., ISBN: 978-3540-89789-7, Springer, Berlin.

45 Kanit T., Forest S., Gailliet I., Mounoury V., Jeulin D. (2003) Determination of the representative volume for random composites: Statistical and numerical approach, Int. J. Solids Struct. 40, 3647-3679.

46 Renard P., Allard D. (2013) Connectivity metrics for subsurface flow and transport, Advances in Water Resources 51, 168-196.

47 Savoye S., Frasca B., Grenut B., Fayette A. (2012) How mobile is iodide in the Callovo-Oxfordian claystones under experimental conditions close to the in situ ones? Journal of Contaminant Hydrology 142-143, 82-92.

Manuscript submitted in September 2015 Manuscript accepted in January 2016 Published online in June 2016

Cite this article as: Y. Song, C.A. Davy and D. Troadec (2016). Gas Breakthrough Pressure (GBP) through Claystones: Correlation with FIB/SEM Imaging of the Pore Volume, Oil Gas Sci. Technol 71, 51. 